Clinical Research Paper

\title{
Efficacy and safety of cisplatin, dexamethasone, gemcitabine and pegaspargase (DDGP) regimen in newly diagnosed, advanced-stage extranodal natural killer/T-cell lymphoma: interim analysis of a phase 4 study NCT01501149
}

\author{
Lei Zhang ${ }^{1,3, *}$, Sisi Jia ${ }^{1,3, *}$, Yangyang $\mathbf{M a}^{1,3, *}$, Ling $\mathrm{Li}^{1,3}$, Xin $\mathbf{L i}^{1,3}$, Xinhua Wang ${ }^{1,3}$, \\ Xiaorui Fu${ }^{1,3}$, Wang Ma ${ }^{1,3}$, Yanru Qinn ${ }^{1,3}$, Wencai $\mathbf{L i}^{2,3}$, Jingjing $\mathbf{W u}^{1,3}$, Zhenchang \\ Sun ${ }^{1,3}$, Xudong Zhang ${ }^{1,3}$, Feifei Nan ${ }^{1,3}$, Yu Chang ${ }^{1,3}$, Zhaoming Li ${ }^{1,3}$, Dandan Zhang ${ }^{2,3}$, \\ Guannan Wang ${ }^{2,3}$, Jiaqin Yan ${ }^{1,3}$, Liping Su${ }^{4}$, Jinghua Wang ${ }^{5}$, Hongwei Xue ${ }^{6}$, \\ Ken H. Young ${ }^{7}$, Mingzhi Zhang ${ }^{1,3}$

\footnotetext{
${ }^{1}$ Department of Oncology, The First Affiliated Hospital of Zhengzhou University, Zhengzhou, Henan, 450000, China

${ }^{2}$ Department of Pathology, The First Affiliated Hospital of Zhengzhou University, Lymphoma Diagnosis and Treatment Center of Henan Province, Zhengzhou, Henan, China

${ }^{3}$ Lymphoma Diagnosis and Treatment Center of Henan Province, Zhengzhou, Henan, 450000, China

${ }^{4}$ Department of Hematology, Shanxi Province Cancer Hospital, Taiyuan, Shanxi, China

${ }^{5}$ Department of Oncology, Nanjing General Hospital of Nanjing Military Command, Nanjing, Jiangsu, China

${ }^{6}$ Department of Oncology, The Affiliated Hospital of Qingdao University, Qingdao, Shandong, China

${ }^{7}$ Department of Hematology, The University of Texas MD Anderson Cancer Center, Houston, TX, USA
} \\ *These authors have contributed equally to this work
}

Correspondence to: Mingzhi Zhang, email: mingzhi_zhang1@163.com

Keywords: extranodal natural killer/T-cell lymphoma, DDGP, chemotherapy, efficacy, safety

Received: November 03, $2015 \quad$ Accepted: May 11, $2016 \quad$ Published: June 17, 2016

\section{ABSTRACT}

To explore a more effective treatment for newly diagnosed, advanced-stage extranodal natural killer/T-cell lymphoma, nasal type (ENKTL), we conducted a phase 4 study of the cisplatin, dexamethasone, gemcitabine, pegaspargase (DDGP) regimen. The primary end point was the 2-year progression-free survival (PFS) after the protocol treatment. Secondary endpoints included response rate (RR), overall survival (OS) and median survival time (MST). The interim analysis included data only from March 2011 to September 2013, who received six cycles of DDGP chemotherapy. A total of 25 eligible patients were enrolled. Seventeen patients $(17 / 24,70.83 \%)$ achieved complete response (CR) and four (4/24, 16.67\%) achieved partial response (PR), three $(3 / 24,12.50 \%)$ had progressive disease (PD). The RR after treatment was $\mathbf{8 7 . 5 0 \%}$. After a median follow-up duration of 24.67 months (range 4-48 months). The 2-year PFS and OS rate were $61.80 \%$ (95\% CI, $42.00 \%$ to $81.60 \%$ ) and 68.50 $\%(95 \%$ CI, $48.70 \%$ to $88.30 \%)$, respectively. The MST was 36.55 months ( $95 \%$ CI, 29.41 months to $\mathbf{4 3 . 7 0}$ months). Grade $3 / 4$ leukopenia occurred in fourteen patients $(58.33 \%)$ and grade $3 / 4$ thrombocytopenia occurred in eleven patients $(45.83 \%)$. Twelve patients (50.00\%) experienced Activated Partial Phromboplastin Ptime (APTT) elongation and fourteen patients (58.33\%) experienced hypofibrinogenemia. In conclusion, DDGP regimen is an effective and tolerated treatment for newly diagnosed, advanced-stage ENKTL. This trial was registered at www.Clinical Trials. gov as \#NCT01501149. 


\section{INTRODUCTION}

Extranodal natural killer /T-cell lymphoma, nasal type (ENKTL) is a rare and highly aggressive lymphoid malignancy with distinct clinical characteristics and dismal outcomes. It shows a peculiar geographic predilection for Asian and South American populations [1]. Most patients with ENKTL have localized disease in the upper aerodigestive tract especially nasal cavity, paranasal sinus, and occasionally in the lung, skin, gastrointestinal tract and testis [2-3]. Concomitant chemoradiotherapy is recommended for localized ENKTL [4-5]. There is still a third of ENKTL patients present with advanced disease [6], for those patients, CHOP (cyclophosphamide, doxorubicin, vincristine, and prednisone) and CHOPlike regiments does not improve survival much (median survival of 2-8 months) [7]. L-asparaginasebased regimens such as L-asparaginase, ifosfamide, methotrexate, etoposide, and dexamethasone (SMILE) or L-asparaginase, methotrexate, and dexamethasone (AspaMetDex) or gemcitabine, oxaliplatin, and L-asparaginase (GELOX) chemotherapy had been tried and the curative effect improved than before [8-11]. However, grade 4 neutropenia was observed in $92 \%$ of the patients who was treated with SMILE regimen [8], and about $30 \%$ patients because the hypersensitivity reactions could not apply L-Asp-based regimens $[12,13]$. The best first-line chemotherapy regimen is not yet established at present, clinical trials are recommended in NCCN Guidelines from 2011 to 2015 year [14].

In order to explore a more effective and safety chemotherapy proposal for ENKTL, from 2009, a series of research on the treatment of ENKTL had been made by Lymphoma Diagnosis and Treatment Center of Henan Province, China. We tested the IC50 of a variety of commonly used chemotherapeutics on SNK-6 cells (a kind of NK/T cell lymphoma line) in vitro experiments including vincristine, anthracycline, bleomycin, dacarbazine, platinum, methotrexate, gemcitabine, L-asparaginase, pegaspargase (a pegylated form of L-asparaginase, not only reduce the risk of hypersensitivity reactions but also increase in plasma half-life when compared with L-asparaginase, has been proved safe and effective in patients with acute lymphoblastic leukemia [15]) et al. We found that gemcitabine $(0.002 \mathrm{ug} / \mathrm{ml})$ has the lowest IC50 value of all the chemotherapeutics. For pegasparaginase and L-asparaginase, the IC50 values were $4.56 \mathrm{IU} / \mathrm{ml}$ and $3.28 \mathrm{IU} / \mathrm{ml}$, respectively. The IC50 value of cisplatin $(3.47 \mathrm{ug} / \mathrm{ml})$ significantly lower than oxaliplatin $(11.610 \mathrm{ug} / \mathrm{ml})$ and carboplatin $(29.03 \mathrm{ug} / \mathrm{ml})$. On the basis of extensive analyses, we formulated a novel pegaspargase-based regimen: cisplatin, dexamethasone, gemcitabine, pegaspargase (DDGP) to treat newly diagnosed ENKTL. From August 2010 to May 2012, our center enrolled 12 newly-diagnosed stage II-IV ENKTL patients treated with DDGP regimen, and 100\% RR was achieved (Ten patients $(10 / 12,83.3 \%)$ achieved CR and two (2/12, 16.7\%) achieved PR) [16]. In addition, Zhiyuan Zhou, Mingzhi Zhang et al. [17] investigated the efficacy and safety of 17 relapsed/refractory ENKTL patients treated with DDGP regimen between July 2011 and December 2012. The RR and the CR rate were $88.2 \%$ and $52.9 \%$, respectively. The 1-year OS rate and 1-year PFS rate were $82.4 \%$ and $64.7 \%$, respectively. In 2011, we registered the clinical trials on the U.S. National Institutes of Health (The Clinical Trial registration number: NCT01501149; Official Title: A Randomized Controlled Multi-center Clinical Trial on Treatment of Stage III/IV NK/T Cell Lymphoma with DDGP Regiment). At present, the clinical trial is still recruiting. Here, we will report the interim analysis results about the DDGP regimen in the treatment of newly diagnosed advanced-stage ENKTL.

\section{RESULTS}

\section{Patients}

From March 2011 to September 2013, a total of 25 Chinese patients were randomly assigned to DDGP group. Histologic diagnosis of all patients was confirmed as ENKTL by the pathologists of our lymphoma center. The baseline characteristics of DDGP group patients are listed in Table 1.

The median age was 40 years (range 17 to 64 years), and the male: female ratio was 14:11. At diagnosis 24 patients $(96.00 \%)$ had upper aerodigestive tract NK/Tcell lymphoma (UAT-NTCL) and one $(4.00 \%)$ had extraupper aerodigestive tract NK/T-cell lymphoma (NUATNTCL). 17 patients $(68.00 \%)$ had newly diagnosed stage III disease, and 8 patients $(32.00 \%)$ had stage IV disease. 12 patients $(48.00 \%)$ had B symptoms at presentation, and elevated lactate dehydrogenase (LDH) was observed in 9 patients $(36.00 \%)$. None of the patients had CNS involvement or bone marrow invasion. Conventional unfavorable factors for the cohort included high prognostic index of 3 to $4(52.00 \%)$.

\section{Treatment response and survival outcomes}

A total of 25 eligible patients were enrolled, a patient lost to follow-up and out of the group after 2 cycles. Twenty patients $(80.00 \%)$ completed six cycles of DDGP chemotherapy. Three patients received five cycles of DDGP regimen. One patient accepted four cycles. The total cycles of DDGP regimen received by all patients were 141, with a median of 5.64 cycles (range, 2-6 cycles). The efficacy was estimated in all the 24 patients $(96.00 \%)$ who received the scheduled treatment (in Table 2). One patient died of brain metastases after four cycles. One patient died from septic shock after five cycles of DDGP regimen. One patient died from multiple organ failure (MOF) after five cycles who achieved CR. 
Table 1: Patients characteristics $(\mathrm{N}=25)$

\begin{tabular}{|c|c|c|}
\hline Characteristic & No. of Patients & $\%$ \\
\hline \multicolumn{3}{|l|}{ Age, years } \\
\hline Median & 40 & \\
\hline Range & 17 to 64 & \\
\hline \multicolumn{3}{|l|}{ Sex } \\
\hline Male & 14 & 56.00 \\
\hline Female & 11 & 44.00 \\
\hline \multicolumn{3}{|l|}{ Subtype of ENKL } \\
\hline UAT-NTCL & 24 & 96.00 \\
\hline NUAT-NTCL & 1 & 4.00 \\
\hline \multicolumn{3}{|l|}{ Stage at enrollment } \\
\hline III & 17 & 68.00 \\
\hline IV & 8 & 32.00 \\
\hline "B" symptoms present & 12 & 48.00 \\
\hline Elevated serum LDH & 9 & 36.00 \\
\hline \multicolumn{3}{|l|}{ Performance status } \\
\hline 0 & 5 & 20.00 \\
\hline 1 & 14 & 56.00 \\
\hline 2 & 6 & 24.00 \\
\hline \multicolumn{3}{|l|}{ NK/T-cell PI score } \\
\hline $0-1$ & 0 & 0.00 \\
\hline 2 & 12 & 48.00 \\
\hline 3 & 8 & 32.00 \\
\hline 4 & 5 & 20.00 \\
\hline
\end{tabular}

One patient rapidly progressed after received five cycles. Thirteen $(13 / 24,54.2 \%)$ patients made dose levels reduction by $20 \%$ due to IV degree of bone marrow suppression.

At the end of treatment, seventeen patients (17/24, $70.83 \%$ ) achieved $\mathrm{CR}$ and four (4/24, 16.67\%) got PR, three $(3 / 24,12.50 \%)$ had PD. The RR and CR rate after treatment were $87.50 \%$ and $70.83 \%$, respectively.

By March 2015, fourteen patients (14/24, 58.33\%) were alive with no evidence of disease (NOD) after a median follow-up of 24.67 months (range 4-48 months). Five patients $(5 / 24,20.83 \%)$ relapsed at the time of 9,13 , 15,18 and 30 months after commencing treatment with DDGP regimen, respectively, and two of them were still alive. One of the three patients with disease progression is still alive. Two patients $(2 / 24,8.33 \%)$ died of MOF and septic shock, respectively. The MST was 36.55 months (95\% CI, 29.41 months to 43.70 months). The 1-year OS rate and 1-year PFS rate were $79.20 \%$ and $75.00 \%$, respectively. The 2-year OS and PFS rate were $68.50 \%$ and $61.8 \%$, respectively. (Figures 1 and 2 ).

\section{Assessment of safety}

Table 3 lists all grade 1 to 4 adverse events (AEs) that occurred in the 24 eligible patients. The major adverse reactions to DDGP regimen were myelosuppression, digestive tract toxicities, liver dysfunction, and coagulation dysfunction (APTT elongation or decrease in fibrinogen). Grade 3/4 leukopenia occurred in fourteen patients $(58.33 \%)$ and grade $3 / 4$ thrombocytopenia occurred in eleven patients $(45.83 \%)$. Twenty-one patients $(87.50 \%)$ were observed digestive tract toxicities. Twelve patients $(50.00 \%)$ had APTT elongation and fourteen patients $(58.33 \%)$ experienced hypofibrinogenemia. There was one patient died from infection which was treatmentrelated. One patient died from MOF. (See Table 4). No pancreatitis and allergic reaction were seen. 
Table 2: Treatment and the long-term outcome of 25 newly diagnosed, advanced-stage ENKTL patients

\begin{tabular}{|c|c|c|c|c|c|c|c|c|}
\hline No. & Sex & Age & Diagnosis stage & Cycles & Response & PFS(m) & OS(m) & Current status \\
\hline 1 & $\mathrm{M}$ & 56 & UAT,III & 2 & PR & Exclude & Exclude & Exclude \\
\hline 2 & M & 34 & UAT,III & 6 & $\mathrm{CR}$ & 48 & 48 & NOD \\
\hline 3 & $\mathrm{~F}$ & 62 & NUAT,IV & 6 & $\mathrm{CR}$ & 18 & 24 & DOD \\
\hline 4 & $\mathrm{~F}$ & 62 & UAT,IV & 6 & PR & 47 & 47 & NOD \\
\hline 5 & $\mathrm{~F}$ & 34 & UAT,III & 6 & $\mathrm{CR}$ & 47 & 47 & NOD \\
\hline 6 & $\mathrm{~F}$ & 26 & UAT,III & 6 & $\mathrm{CR}$ & 30 & 46 & Live \\
\hline 7 & $\mathrm{~F}$ & 47 & UAT,IV & 6 & $\mathrm{CR}$ & 9 & 9 & DOD \\
\hline 8 & M & 54 & UAT,III & 6 & $\mathrm{CR}$ & 41 & 41 & NOD \\
\hline 9 & $\mathrm{~F}$ & 26 & UAT,III & 5 & $\mathrm{PD}$ & 5 & 11 & DOD \\
\hline 10 & M & 54 & UAT,IV & 6 & $\mathrm{CR}$ & 13 & 14 & DOD \\
\hline 11 & $\mathrm{~F}$ & 29 & UAT,III & 6 & $\mathrm{CR}$ & 15 & 37 & Live \\
\hline 12 & M & 54 & UAT,III & 5 & $\mathrm{CR}$ & 4 & 4 & DUD \\
\hline 13 & M & 17 & UAT,III & 6 & PR & 33 & 33 & NOD \\
\hline 14 & $\mathrm{~F}$ & 43 & UAT,III & 6 & $\mathrm{CR}$ & 32 & 32 & NOD \\
\hline 15 & M & 44 & UAT,III & 5 & $\mathrm{CR}$ & 7 & 7 & DUD \\
\hline 16 & $\mathrm{M}$ & 31 & UAT,III & 6 & $\mathrm{CR}$ & 29 & 29 & NOD \\
\hline 17 & $\mathrm{M}$ & 42 & UAT,III & 6 & PD & 6 & 26 & Live \\
\hline 18 & $\mathrm{M}$ & 23 & UAT,IV & 4 & PD & 4 & 6 & DOD \\
\hline 19 & F & 37 & UAT,III & 6 & PR & 24 & 24 & NOD \\
\hline 20 & $\mathrm{M}$ & 24 & UAT,IV & 6 & $\mathrm{CR}$ & 11 & 11 & NOD \\
\hline 21 & F & 35 & UAT,III & 6 & PR & 21 & 21 & NOD \\
\hline 22 & $\mathrm{M}$ & 48 & UAT,IV & 6 & $\mathrm{CR}$ & 20 & 20 & NOD \\
\hline 23 & F & 40 & UAT,III & 6 & $\mathrm{CR}$ & 19 & 19 & NOD \\
\hline 24 & M & 64 & UAT,III & 6 & $\mathrm{CR}$ & 18 & 18 & NOD \\
\hline 25 & $\mathrm{M}$ & 18 & UAT,IV & 6 & $\mathrm{CR}$ & 18 & 18 & NOD \\
\hline
\end{tabular}

Abbreviations: M male, F female, ENKTL extranodal NK/Tcell lymphoma,

UAT upper aerodigestive tract, DDGP gemcitabine, pegaspargase, cisplatin, and dexamethasone, CR complete response, PR partial response, PD progressive disease, PFS progression-free survival, OS overall survival, $m$ month, DOD dead of disease, DUD dead unrelated to disease, NOD no evidence of disease

\section{DISCUSSION}

In our study, we have investigated the use of a pegaspargase-based chemotherapy for the treatment of newly-diagnosed, stage III and stage IV ENKTL, and the results indicate that the efficacy of DDGP regimen was excellent.

The enzyme L-Asp exerts its antitumor effects through the depletion of the essential amino acid L-asparagine, leading to inhibition of protein synthesis in tumor cells [18]. Nagafuji et al. [19] first reported the application of L-Asp in a patient with relapsed nasal NK/
T-cell lymphoma after autologous peripheral blood stem cell transplantation. Durable remission was achieved and this patient was alive with NOD after 18 months of followup. However, the higher proportion of allergic reaction limiting the use of L-asparaginase [13]. Pegasparaginase, a modified form of L-asparaginase, had greatly reduced the incidence of allergic reaction. Moreover, it has a longer elimination half-life which allows for a considerable reduction in the frequency of drug administration for patients. Reyes Jr V E et al. [20] reported that two patients with relapsed/refractory ENKTL received single-agent pegaspargase, and both entered CR. 
Gemcitabine is a kind of cell cycle specificity antitumor drugs, mainly killing the tumor cells in S phase (DNA synthesis), as well as blocking the transition process of cell proliferation from G1 phase to S phase. Gemcitabine proved to be effective in pretreated patients with peripheral T-cell lymphoma, especially cutaneous T-cell lymphoma, even in the long term, which can provide rationale for moving it to the frontline therapy $[21,22]$. However, because of the rarity of ENKTL, the efficacy of gemcitabine in the treatment of ENKTL is not well known. A retrospective study of gemcitabinecontaining regimen for refractory or relapsed ENKTL indicated that gemcitabine was effective in a subset of pretreated ENKTL patients and can be considered as a salvage option [23]. Our previous work confirmed that gemcitabine $(0.002 \mathrm{ug} / \mathrm{ml})$ has the lowest IC50 value of all the chemotherapeutics, and $100 \%$ ORR was observed in our reliminary experiments [16].

In this study, our interim analysis showed a $\mathrm{CR}$ rate of $70.83 \% \%$ and a PR rate of $16.67 \%$, giving an ORR of $87.50 \%$. The CR rate was superior than those treated with
SMILE regimen [8, 24], which was similar to those newlydiagnosed localized disease treated with GELOX followed by radiotherapy (74.1\%) [10]. The CR rate and survival were much better than historical data using anthracyclinebased chemotherapy $[1,11,25]$. (Table 5)

With regard to the safety of DDGP, the major side effects include bone marrow suppression and coagulant function abnormality. About half of the patients experienced grade 3 and 4 neutropenia. More than half of the patients have high grade thrombocytopenia. To avoid severe adverse events, the use of Granulocyte colony-stimulation factor (G-CSF), recombinant human thrombopoietin (TPO) or Interleukin-11 (IL-11) is essential. Other support treatments such as infection prevention and platelet transfusion were also necessary when patients were in leukopenia and thrombocytopenia status during or after chemotherapy. In case of grade 4 adverse events, doses of chemotherapy agents were reduced to $80 \%$ of their previous levels in the next course. In our study, about half of patients experienced $1 / 2$ level of liver dysfunction (ALT/AST elevation) and coagulation dysfunction (prolonged APTT

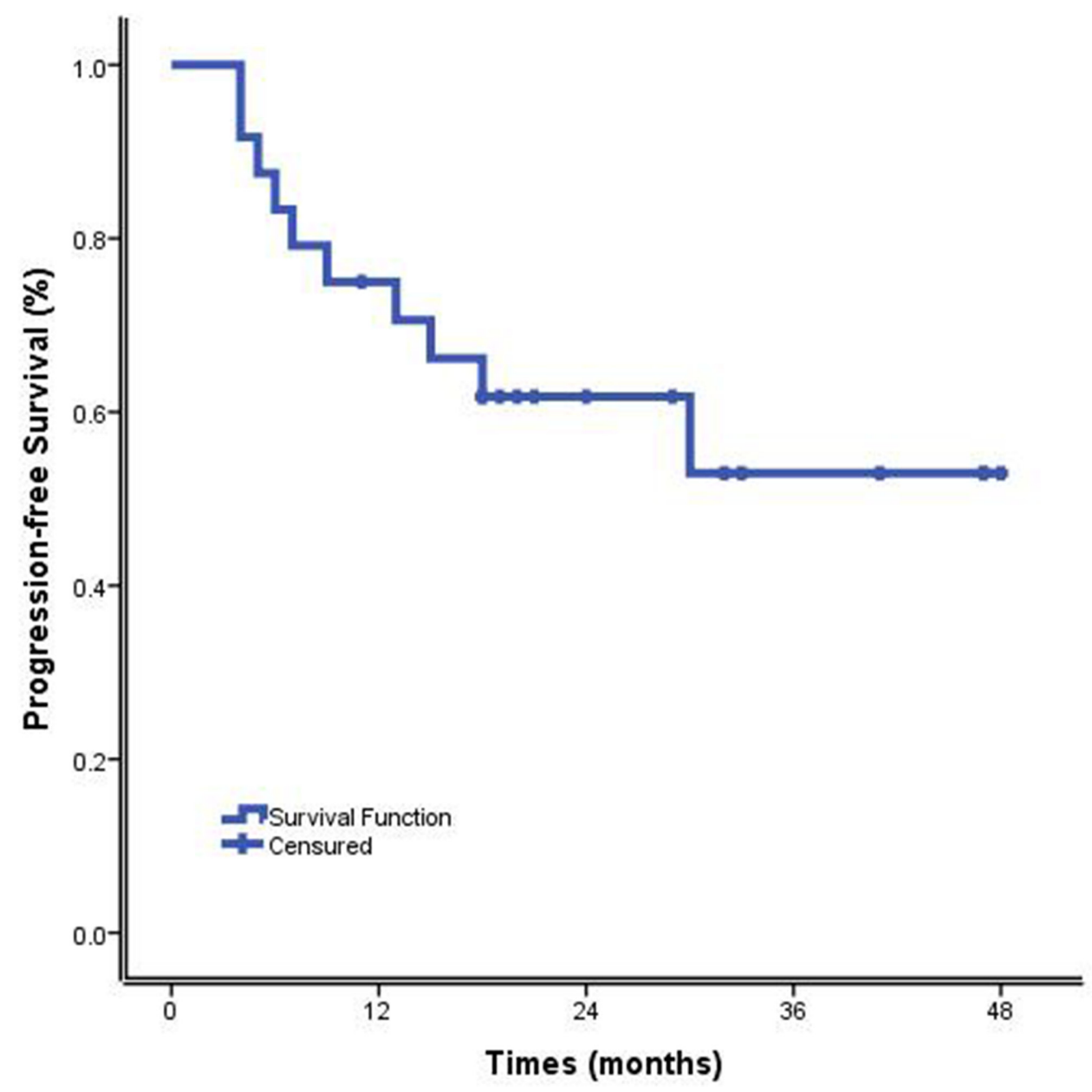

Figure 1: Progression-free survival of cisplatin, dexamethasone, gemcitabine, pegaspargase(DDGP) chemotherapy for patients with newly diagnosed, advanced-stage ENKTL. 


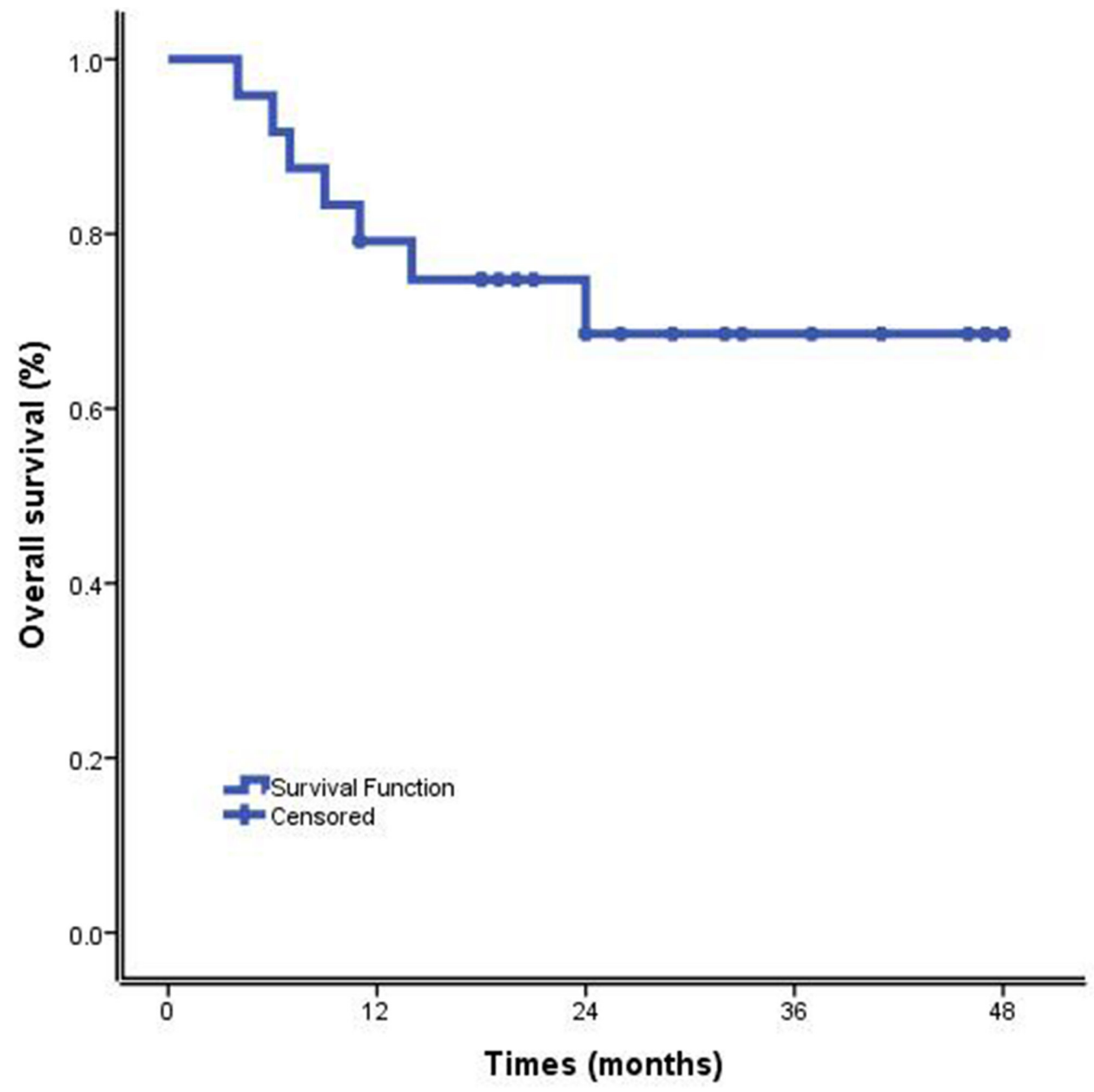

Figure 2: Overall survival of cisplatin, dexamethasone, gemcitabine, pegaspargase (DDGP) chemotherapy for patients with newly diagnosed, advanced-stage ENKTL.

Table 3: Treatment-related toxicities

\begin{tabular}{lcccc}
\hline Adverse events & \multicolumn{2}{c}{ Grade 1/2 } & \multicolumn{2}{c}{ Grade3/4 } \\
\cline { 2 - 5 } & No. & $\mathbf{\%}$ & No. & \% \\
\hline Hematologic & & & & 58.33 \\
Leukopenia & 9 & 37.50 & 14 & 75.00 \\
Neutropenia & 5 & 20.83 & 18 & 37.50 \\
Anemia & 14 & 58.33 & 9 & 45.83 \\
Thrombocytopenia & 6 & 25.00 & 11 & 29.17 \\
Nonhematologic & & & & 4.17 \\
Nausea/vomiting & 14 & 58.33 & 7 & - \\
ALT/AST elevation & 14 & 58.33 & 1 & (Continued) \\
Increased BUN & 2 & 8.33 & 0 & \\
& & & &
\end{tabular}




\begin{tabular}{lcccc}
\hline Adverse events & \multicolumn{2}{c}{ Grade 1/2 } & & Grade3/4 \\
\cline { 2 - 5 } & No. & \% & No. & \% \\
\hline Heighten of hemodiastase & & 0 & \\
Increased urinary amylase & & 0 & \\
Coagulation disorders & & & \\
APTT elongation & & $12(50.00 \%)$ & \\
Hypofibrinogenemia & $14(58.33 \%)$ & \\
\hline
\end{tabular}

Table 4: Seven death patients

\begin{tabular}{lcccccccccc}
\hline No. & Sex & Age & B symptoms & LDH & ECOG & Cycles & Response & Relapse & $\begin{array}{c}\text { Treatment } \\
\text { after PD/ } \\
\text { relapse }\end{array}$ & Death causes \\
\hline 3 & F & 62 & NO & High & 2 & 6 & CR & YES & Chemotherapy & lymphoma \\
7 & F & 47 & NO & Normal & 1 & 6 & CR & YES & NO & lymphoma \\
9 & F & 26 & NO & Normal & 0 & 5 & PD & -- & RT & lymphoma \\
10 & M & 54 & YES & High & 1 & 6 & CR & YES & RT & lymphoma \\
12 & M & 54 & NO & Normal & 0 & 5 & CR & --- & --- & Shock* \\
15 & M & 44 & YES & Normal & 2 & 5 & CR & --- & --- & MOF** \\
18 & M & 23 & NO & Normal & 1 & 4 & PD & --- & $\begin{array}{c}\text { Alleviative } \\
\text { treatment }\end{array}$ & lymphoma \\
\hline
\end{tabular}

Abbreviations: ECOG Eastern Cooperative Oncology Group, MOF multiple organ failure, RT Radiotherapy

*After five cycles of chemotherapy, this patient experienced grade 4 neutropenia, combination of intestinal infection, led to the deaths of septic shock.

** After chemotherapy, the lymphoma of this patients gradually disappear, but his performance status decreased gradually, finally he died of multiple organ failure.

Table 5: Study comparison with recent prospective studies of ENKTL

\begin{tabular}{|c|c|c|c|c|c|c|}
\hline \multirow[t]{2}{*}{ Author, year } & \multirow[t]{2}{*}{ Disease status } & \multirow[t]{2}{*}{ No. Of patients } & \multirow[t]{2}{*}{ Treat } & \multirow[t]{2}{*}{ CR rate } & \multicolumn{2}{|c|}{ Survival } \\
\hline & & & & & OS & PFS \\
\hline $\begin{array}{l}\text { Mingzhi zhang } \\
\text { et al. } 2015 \text { (this } \\
\text { study) }\end{array}$ & $\begin{array}{l}\text { Newly- } \\
\text { diagnosed }\end{array}$ & Stage III/IV: 25 & DDGP & $70.83 \%$ & $\begin{array}{l}79.20 \%(1-y r) \\
68.50 \%(2-y r)\end{array}$ & $\begin{array}{l}75.00 \%(1-y r) \\
61.80 \%(2-y r)\end{array}$ \\
\hline Lin et al. 2013 & $\begin{array}{l}\text { Newly- } \\
\text { diagnosed }\end{array}$ & $\begin{array}{c}\text { Stage I/II: } 30 \\
\text { Stage III/IV: } 6\end{array}$ & $\mathrm{CHOP}-\mathrm{L} \pm \mathrm{RT}$ & $\begin{array}{l}90 \% \\
50 \%\end{array}$ & $\begin{array}{c}88.3 \%(2-y r) \\
50 \%(2-y r)\end{array}$ & $\begin{array}{c}89.5 \% \text { (2-yr) } \\
50 \%(2-\mathrm{yr})\end{array}$ \\
\hline $\begin{array}{l}\text { Wang L, et al. } \\
2013\end{array}$ & $\begin{array}{c}\text { Newly } \\
\text {-diagnosed }\end{array}$ & Stage IE/IIE: 27 & GELOX \pm RT & $74.1 \%$ & $86 \%$ (2-yr) & $86 \%$ (2-yr) \\
\hline $\begin{array}{l}\text { Kwong YL, } \\
\text { et al. } 2012\end{array}$ & $\begin{array}{l}\text { Newly- } \\
\text { diagnosed } \\
\text { Relapse/ } \\
\text { refractory }\end{array}$ & $\begin{array}{c}\text { Newly } \\
\text { diagnosed } \\
\text { Stage I/II:17 } \\
\text { Stage IV: } 26 \\
\text { relapse/ } \\
\text { refractory: } 44\end{array}$ & SMILE & $66 \%$ & $\begin{array}{c}\text { Newly } \\
\text { diagnosed } \\
47.4 \%(5-y r)\end{array}$ & $\begin{array}{c}\text { Newly } \\
\text { diagnosed } \\
60.0 \%(4-y r)\end{array}$ \\
\hline
\end{tabular}




\begin{tabular}{|c|c|c|c|c|c|c|}
\hline \multirow[t]{2}{*}{ Author, year } & \multirow[t]{2}{*}{ Disease status } & \multirow[t]{2}{*}{ No. Of patients } & \multirow[t]{2}{*}{ Treat } & \multirow[t]{2}{*}{ CR rate } & \multicolumn{2}{|c|}{ Survival } \\
\hline & & & & & OS & PFS \\
\hline $\begin{array}{l}\text { Yamaguchi M, } \\
\text { et al. } 2011\end{array}$ & $\begin{array}{l}\text { Newly- } \\
\text { diagnosed } \\
\text { Relapse/ } \\
\text { refractory }\end{array}$ & $\begin{array}{l}\text { Newly- } \\
\text { diagnosed } \\
\text { Stage IV: } 20 ; \\
\text { relapse/ } \\
\text { refractory: } 18\end{array}$ & SMILE & $45 \%$ & $55 \%(1-\mathrm{yr})$ & --- \\
\hline $\begin{array}{l}\text { Jaccard et al. } \\
2011\end{array}$ & $\begin{array}{l}\text { Relapse/ } \\
\text { refractory }\end{array}$ & 19 & AspaMetDex & $61 \%$ & --- & $\begin{array}{l}\text { Median PFS: } \\
12.2 \text { months }\end{array}$ \\
\hline
\end{tabular}

and hypofibrinogenemia). Fortunately, no patients died of severe liver damage or coagulation dysfunction, which may be caused by pegaspargase. However, liver function and coagulation function still need to be closely monitored. In case of hypofibrinogenemia caused by pegaspargase, fresh frozen plasma (FFP), cryoprecipitate or human fibrinogen should be timely applied. Also, glutathlone or compound glycyrrhizin injection could be used to support liver protection therapy. The usual frequency of allergic reaction to pegaspargase is about $2 \%$. However, no allergic reaction to pegaspargase occurred in our study.

In conclusion, this prospective study demonstrates that DDGP is an effective and tolerated chemotherapy for patients with newly diagnosed, advanced-stage ENKTL and indicates the potential of this regimen as a first-line therapy against this disease. But the small sample size, and short follow-up period suggest that our findings need to be further investigated with a larger patient group and longer follow-up period. At present, our clinical trial is still recruiting to evaluate its efficiency and safety.

\section{MATERIALS AND METHODS}

\section{Study design}

This was an open label, randomized, controlled, multi-center, phase 4 study of DDGP chemotherapy treated with newly diagnosed advanced-stage ENKTL. The study was approved by the Human Subjects Committee and institutional review board at each participating institution, and all patients signed an informed consent document describing the investigational nature of the proposed treatment. The primary end point was the 2-year PFS after the protocol treatment. Secondary outcome measures included RR, OS and MST. The PFS was measured from the date of treatment until disease progression or death from any cause or the last follow-up. The RR was defined as the proportion of all patients who experienced CR and PR. OS was defined as the time from treatment until death from any cause or the last follow-up. MST refered to the survival time when the cumulative survival rate was 50 percent. The study was conducted in accordance with the Declaration of Helsinki and was registered with www.Clinical Trials. gov as \#NCT01501149.

Eligible patients were randomly assigned by the study coordinating center to treatment with DDGP or Modified SMILE alone. Patients treated with DDGP received the combination of $20 \mathrm{mg}$ of cisplatin per square meter of body-surface area on days $1-4,15 \mathrm{mg}$ of dexamethasone per square meter on days $1-5,800$ $\mathrm{mg}$ of gemcitabine per square meter on day 1 and day 8 , and 2,500 IU of pegaspargase per square meter on day 1 . They were treated every 21 days for six cycles of DDGP. Patients treated with Modified SMILE received methotrexate $2 \mathrm{~g} / \mathrm{m}^{2}$ (6 hours), dexamethasone $40 \mathrm{mg} / \mathrm{d}$ $\mathrm{d} 2-4$, ifosfamide $1,500 \mathrm{mg} / \mathrm{m}^{2} \mathrm{~d} 2-4$, L-asparaginase 6,000 $\mathrm{U} / \mathrm{m}^{2} \mathrm{~d} 3-9$, etoposide $100 \mathrm{mg} / \mathrm{m}^{2} \mathrm{~d} 2-4$, Mesna $300 \mathrm{mg} /$ $\mathrm{m}^{2} \mathrm{~d} 2-4$. Cycles were repeated every 21 days. Six courses were planned as the protocol treatment.

The doses of chemotherapy drugs were reduced to $80 \%$ of their previous dose levels in patients who had grade 4 adverse events, except for pegaspargase. Tumor responses were assessed every two cycles of chemotherapy. During the treatment, patients were routinely monitored for blood tests, serum chemistry, and coagulation function. G-CSF and TPO or IL-11 were given to patients who developed neutropenia and thrombocytopenia as support therapy. The patients were withdrawn from the study when they meet any conditions as follows: patients' conditions deteriorated so as to transfer to other treatments immediately including disease progression; patients experienced severe and intolerant toxicity reaction; chemotherapy delayed more than two weeks; patients asked for dropping out of the study or the researchers thought the medical need to withdraw from this study.

\section{Patients}

Inclusion Criteria were as follows: (1) Age range 14-70 years old; (2) ECOG performance status 0-2; (3) Estimated survival time $>3$ months; (4) Histological 
confirmed NK/T cell lymphoma, nasal-type according to WHO classification [26]; (5) The NSS [27] stage III or IV; (6) None of chemotherapy or radiotherapy has been previously used; (7) None of chemotherapy contraindication: hemoglobin $\geq 90 \mathrm{~g} / \mathrm{dl}$, neutrophil $\geq$ $1.5 \times 10^{9} / \mathrm{L}$, platelet $\geq 100 \times 10^{9} / \mathrm{L}$, ALT and AST $\leq 2 \times$ upper limitation of normal (ULN), serum bilirubin $\leq 1.5 \times \mathrm{ULN}$, serum creatine $\leq 1.5 \times \mathrm{ULN}$, Serum Albumin $\geq 30 \mathrm{~g} / \mathrm{L}$, serum plasminogen is normal; (8) At least one measurable lesion; (9) None of other serious diseases, cardiopulmonary function is normal; (10) Pregnancy test of women at reproductive age must be negative; (11) Patients could be followed up; (12) None of other relative treatments including the traditional Chinese medicine, immunotherapy, biotherapy except anti-bone metastasis therapy and other symptomatic treatments; (13) Volunteers who signed informed consent.

The exclusion criteria included: (1) Disagreement on blood sample collection; (2) Patients allergic of any of drug in this regimen or with metabolic disorder; (3) Pregnant or lactating women; (4) Serious medical illness likely to interfere with participation; (5) Serious infection; (6) Primitive or secondary tumors of central nervous system; (7) Chemotherapy or radiotherapy contraindication; (8) The evidence of CNS metastasis; (9) History of peripheral nervous disorder or dysphrenia; (10) Patients participating in other clinical trials; (11) Patients taking other antitumor drugs; (12) Patients estimated to be unsuitable by investigator.

After patients enrollment, their pathological data were reviewed by pathologists based on the WHO classification [16]. Proven NK/T-cell type by immuneohistochemistry (cytoplasmic CD3 $\varepsilon^{+}, \mathrm{CD} 20$-phenotype, a cytotoxic profile, and markers of EBV by in situ hybridization).

Clinical stage based on the NSS which was established by Tongyu Lin [27]. Stage III was defined localized disease with regional lymph node involvement (cervical lymph nodes); and stage IV: disseminated disease (lymph nodes on both sides of diaphragm, multiple extranodal site). B symptoms were defined as unexplained fever with temperature above $38^{\circ} \mathrm{C}$, night sweats, and unexplained weight loss of more than $10 \%$ of the usual body weight in the 6 months before diagnosis. The NK/Tcell prognostic index score includes B symptoms, AnnArbor stage III/IV, elevated serum LDH level, and regional lymphadenopathy [28].

\section{Assessment of efficacy and adverse events}

The responses were assessed according to criteria modified from the 2010 NCCN response criteria about non-Hodgkin's lymphoma [29]. CR was defined as no evidence of disease. PR was defined as a reduction of at least $50 \%$ of the pretreatment tumor burden without the occurrence of new lesions at the restaging. PD was defined as a greater than $50 \%$ increase in the sum of tumor lesions or the emergence of one or more new lesions or clinical symptoms that indicate disease progression. Stable disease (SD) was defined as any response that did not fall into the other defined categories.

All adverse events were assessed at each cycle from the first day of the regimen until one month after the last treatment and graded according to the National Cancer Institute Common Toxicity Criteria, Version 3.0.

\section{Statistical analysis}

The SPSS Statistics 21.0 software was used to data analysis. The Kaplan-Meier method was used to perform survival analysis for OS, PFS and MST. The 95\% CI were calculated for PFS and OS. All CIs reported were 2-sided.

Toxicity was monitored continuously throughout the study, with descriptive statistics provided of observed events. Toxicities reported were the worst-grade toxicities per patient during the induction period and during the maintenance period.

\section{ACKNOWLEDGMENTS}

We would like to thank all of the treating physicians of the Lymphoma Diagnosis and Treatment Center of Henan Province, Shanxi Provence Cancer Hospital, Nanjing General Hospital of Nanjing Military Command, The Affiliated Hospital of Qingdao University, China for allowing us to include their patients.In addition, we greatly appreciate the help of Dr. Wencai Li, Dandan Zhang and Guannan Wang in ENKTL pathological diagnosis.

\section{CONFLICTS OF INTEREST}

The authors have declared no conflicts of interest.

\section{FUNDING}

This study was supported by the National Natural Science Foundation of China (NSFC) (contract/grant number: 81172118) and Medical science and technology plan projects of Henan province, China (contract/grant number: 201302001).

\section{REFERENCES}

1. Au WY, Weisenburger DD, Intragumtornchai T, Nakamura S, Kim WS, Sng I, Vose J, Armitage JO, Liang R. Clinical differences between nasal and extranasal natural killer/Tcell lymphoma: a study of 136 cases from the International Peripheral T-Cell Lymphoma Project. Blood. 2009; 113: 3931-3937.

2. Tse E, Kwong YL. How I treat NK/T-cell lymphomas. Blood. 2013; 121: 4997-5005.

3. Kim SJ, Jung HA, Chuang SS, Hong H, Guo CC, Cao J, Hong XN, Suzuki R, Kang HJ, Won JH, Chng WJ, Kwong YL, Suh C, et al. Kim WS. Extranodal natural killer/T-cell 
lymphoma involving the gastrointestinal tract: analysis of clinical features and outcomes from the Asia Lymphoma Study Group. J Hematol Oncol. 2013; 6: 86.

4. Yamaguchi $M$, Tobinai $K$, Oguchi $M$, Ishizuka $N$, Kobayashi Y, Isobe Y, Ishizawa K, Maseki N, Itoh K, Usui N, Wasada I, Kinoshita T, Ohshima K, et al. Oshimi K. Phase I/II study of concurrent chemoradiotherapy for localized nasal natural killer/T-cell lymphoma: Japan Clinical Oncology Group Study JCOG0211. J Clin Oncol. 2009; 27: 5594-5600.

5. Kim SJ, Kim K, Kim BS, Kim CY, Suh C, Huh J, Lee SW, Kim JS, Cho J, Lee GW, Kang KM, Eom HS, Pyo $\mathrm{HR}$, et al. Kim WS. Phase II trial of concurrent radiation and weekly cisplatin followed by VIPD chemotherapy in newly diagnosed, stage IE to IIE, nasal, extranodal NK/TCell Lymphoma: Consortium for Improving Survival of Lymphoma study. J Clin Oncol. 2009; 27: 6027-6032.

6. Lim ST, Hee SW, Quek R, Lim LC, Yap SP, Loong EL, Sng I, Tan LH, Ang MK, Ngeow J, Tham CK, Ngo L, Tan MH, et al. Tao M. Comparative analysis of extra-nodal NK/Tcell lymphoma and peripheral T-cell lymphoma: significant differences in clinical characteristics and prognosis. Eur $\mathrm{J}$ Haematol. 2008; 80: 55-60.

7. Suzuki R, Suzumiya J, Yamaguchi M, Nakamura S, Kameoka J, Kojima H, Abe M, Kinoshita T, Yoshino T, Iwatsuki K, Kagami Y, Tsuzuki T, Kurokawa M, et al. Oshimi K. Prognostic factors for mature natural killer (NK) cell neoplasms: aggressive NK cell leukemia and extranodal NK cell lymphoma, nasal type. Ann Oncol. 2010; 21: 1032-1040.

8. Yamaguchi M, Kwong YL, Kim WS, Maeda Y, Hashimoto C, Suh C, Izutsu K, Ishida F, Isobe Y, Sueoka E, Suzumiya J, Kodama T, Kimura H, et al. Suzuki R. Phase II study of SMILE chemotherapy for newly diagnosed stage IV, relapsed, or refractory extranodal natural killer (NK)/T-cell lymphoma, nasal type: the NK-Cell Tumor Study Group study. J Clin Oncol. 2011; 29: 4410-4416.

9. Jaccard A, Gachard N, Marin B, Rogez S, Audrain M, Suarez F, Tilly H, Morschhauser F, Thieblemont C, Ysebaert L, Devidas A, Petit B, de Leval L, et al. Hermine O. Efficacy of L-asparaginase with methotrexate and dexamethasone (AspaMetDex regimen) in patients with refractory or relapsing extranodal NK/T-cell lymphoma, a phase 2 study. Blood. 2011; 117: 1834-1839.

10. Wang L, Wang ZH, Chen XQ, Li YJ, Wang KF, Xia YF, Xia ZJ. First-line combination of gemcitabine, oxaliplatin, and L-asparaginase (GELOX) followed by involved-field radiation therapy for patients with stage IE/IIE extranodal natural killer/T-cell lymphoma. Cancer. 2013; 119: 348-355.

11. Lin N, Song Y, Zheng W, Tu M, Xie Y, Wang X, Ping L, Ying Z, Zhang C, Deng L, Liu W, Zhu J. A prospective phase II study of L-asparaginase- CHOP plus radiation in newly diagnosed extranodal NK/T-cell lymphoma, nasal type. J Hematol Oncol. 2013; 6: 44.
12. Woo MH, Hak LJ, Storm MC, Sandlund JT, Ribeiro RC, Rivera GK, Rubnitz JE, Harrison PL, Wang B, Evans WE, Pui CH, Relling MV. Hypersensitivity or development of antibodies to asparaginase does not impact treatment outcome of childhood acute lymphoblastic leukemia. J Clin Oncol. 2000; 18: 1525-1532.

13. Silverman LB, Supko JG, Stevenson KE, Woodward C, Vrooman LM, Neuberg DS, Asselin BL, Athale UH, Clavell L, Cole PD, Kelly KM, Laverdiere C, Michon B, et al. Sallan SE. Intravenous PEG-asparaginase during remission induction in children and adolescents with newly diagnosed acute lymphoblastic leukemia. Blood. 2010; 115: 1351-1353.

14. Yamaguchi M. Current and future management of NK/Tcell lymphoma based on clinical trials. Int J Hematol. 2012; 96: 562-571.

15. Escherich G, Zur SU, Zimmermann M, Horstmann MA. Clofarabine in combination with pegylated asparaginase in the frontline treatment of childhood acute lymphoblastic leukaemia: a feasibility report from the CoALL 08-09 trial. Br J Haematol. 2013; 163: 240-247.

16. Li L, Zhang C, Zhang L, Li X, Wu JJ, Sun ZC, Fu XR, Wang XH, Chang Y, Wang R, Qiu YJ, Zhang MZ. Efficacy of a pegaspargase-based regimen in the treatment of newlydiagnosed extranodal natural killer/T-cell lymphoma. Neoplasma. 2014; 61: 225-232.

17. Zhou Z, Li X, Chen C, Li X, Zhang L, Li L, Wang X, Ma W, Fu X, Wu J, Sun Z, Zhang X, Li Z, et al. Zhang M. Effectiveness of gemcitabine, pegaspargase, cisplatin, and dexamethasone (DDGP) combination chemotherapy in the treatment of relapsed/refractory extranodal NK/T cell lymphoma: a retrospective study of 17 patients. Ann Hematol. 2014; 93: 1889-1894.

18. Yong W, Zheng W, Zhu J, Zhang Y, Wang X, Xie Y, Lin $\mathrm{N}, \mathrm{Xu} \mathrm{B}, \mathrm{Lu} \mathrm{A}, \mathrm{Li} \mathrm{J}$. L-asparaginase in the treatment of refractory and relapsed extranodal NK/T-cell lymphoma, nasal type. Ann Hematol. 2009; 88: 647-652.

19. Nagafuji K, Fujisaki T, Arima F, Ohshima K. $\mathrm{L}$-asparaginase induced durable remission of relapsed nasal NK/T-cell lymphoma after autologous peripheral blood stem cell transplantation. Int J Hematol. 2001; 74: 447-450.

20. Reyes VJ, Al-Saleem T, Robu VG, Smith MR. Extranodal NK/T-cell lymphoma nasal type: efficacy of pegaspargase. Report of two patients from the United Sates and review of literature. Leuk Res. 2010; 34: e50-e54.

21. Zinzani PL, Venturini F, Stefoni V, Fina M, Pellegrini C, Derenzini E, Gandolfi L, Broccoli A, Argnani L, Quirini F, Pileri S, Baccarani M. Gemcitabine as single agent in pretreated T-cell lymphoma patients: evaluation of the longterm outcome. Ann Oncol. 2010; 21: 860-863.

22. Mahadevan D, Unger JM, Spier CM, Persky DO, Young F, LeBlanc M, Fisher RI, Miller TP. Phase 2 trial of combined cisplatin, etoposide, gemcitabine, and methylprednisolone (PEGS) in peripheral T-cell non-Hodgkin lymphoma: 
Southwest Oncology Group Study S0350. Cancer. 2013; 119: 371-379.

23. Ahn HK, Kim SJ, Hwang DW, Ko YH, Tang T, Lim ST, Kim WS. Gemcitabine alone and/or containing chemotherapy is efficient in refractory or relapsed NK/Tcell lymphoma. Invest New Drugs. 2013; 31: 469-472.

24. Kwong YL, Kim WS, Lim ST, Kim SJ, Tang T, Tse E, Leung AY, Chim CS. SMILE for natural killer/T-cell lymphoma: analysis of safety and efficacy from the Asia Lymphoma Study Group. Blood. 2012; 120: 2973-2980.

25. Jaccard A, Petit B, Girault S, Suarez F, Gressin R, Zini JM, Coiteux V, Larroche C, Devidas A, Thieblemont C, Gaulard P, Marin B, Gachard N, et al. Hermine O. L-asparaginase-based treatment of 15 western patients with extranodal NK/T-cell lymphoma and leukemia and a review of the literature. Ann Oncol. 2009; 20: 110-116.
26. Sabattini E, Bacci F, Sagramoso C, Pileri SA. WHO classification of tumours of haematopoietic and lymphoid tissues in 2008: an overview. Pathologica. 2010; 102: 83-87.

27. Tongyu Lin, Huangming Hong, Chaoyong Liang. Extranodal natural killer T-cell lymphoma, nasal-type-A new staging system from CSWOG-A multicenter study, J Clin Oncol 32:5s, 2014 (suppl; abstr 8552).

28. Lee J, Suh C, Park YH, Ko YH, Bang SM, Lee JH, Lee DH, Huh J, Oh SY, Kwon HC, Kim HJ, Lee SI, Kim JH, et al. Kim WS. Extranodal natural killer T-cell lymphoma, nasaltype: a prognostic model from a retrospective multicenter study. J Clin Oncol. 2006; 24: 612-618.

29. Zelenetz AD, Abramson JS, Advani RH, Andreadis CB, Byrd JC, Czuczman MS, Fayad L, Forero A, Glenn MJ, Gockerman JP, Gordon LI, Harris NL, Hoppe RT, et al. Yunus F. NCCN Clinical Practice Guidelines in Oncology: non-Hodgkin's lymphomas. J Natl Compr Canc Netw. 2010; 8: 288-334. 